\title{
Large triglyceride-rich lipoproteins in hypertriglyceridemia are associated with the severity of acute pancreatitis in experimental mice
}

Yue Zhang ${ }^{1}$, Wenhua He${ }^{1}$, Cong He ${ }^{1}$, Jianhua Wan ${ }^{1}$, Xiao Lin ${ }^{2,3}$, Xi Zheng ${ }^{1}$, Lei Li ${ }^{1}$, Xueyang Li $i^{1}$ Xiaoyu Yang ${ }^{1}$,

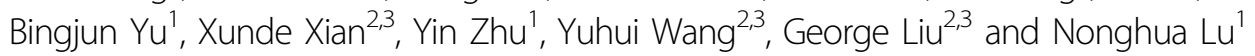

\begin{abstract}
Hypertriglyceridemia severity is linked to acute pancreatitis prognosis, but it remains unknown why a portion of severe hypertriglyceridemia patients do not develop severe acute pancreatitis. To investigate whether hypertriglyceridemia subtypes affect acute pancreatitis progression, we analyzed two genetically modified hypertriglyceridemia mouse models - namely, glycosylphosphatidylinositol high-density lipoprotein binding protein 1 knockout (Gpihbp1-/-) and apolipoprotein C3 transgenic (ApoC3-tg) mice. Acute pancreatitis was induced by 10 intraperitoneal caerulein injections. Biochemical assays and pathological analysis were performed for the severity evaluation of acute pancreatitis. Plasma triglyceride-rich lipoproteins (TRLs), including chylomicrons and very low-density lipoprotein (VLDL), were collected via ultracentrifugation to evaluate their cytotoxic effects on primary pancreatic acinar cells (PACs). We found that the particle sizes of Gpihbp1-/- TRLs were larger than ApoC3-tg TRLs. Severe pancreatic injury with large areas of pancreatic necrosis in the entire lobule was induced in Gpihbp1-/- mice when plasma triglyceride levels were greater than $2000 \mathrm{mg} / \mathrm{dL}$. However, ApoC3-tg mice with the same triglyceride levels did not develop large areas of pancreatic necrosis, even upon the administration of poloxamer 407 to further increase triglyceride levels. Meanwhile, in the acute pancreatitis model, free fatty acids (FFAs) in the pancreas of Gpihbp1-/mice were greater than in ApoC3-tg mice. TRLs from Gpihbp1-/- mice released more FFAs and were more toxic to PACs than those from ApoC3-tg mice. Chylomicrons from patients showed the same effects on PACs as TRLs from Gpihbp1 -/ - mice. Gpihbp1-/- mice with triglyceride levels below 2000 mg/dL had milder pancreatic injury and less incidence of pancreatic necrosis than those with triglyceride levels above $2000 \mathrm{mg} / \mathrm{dL}$, similar to Gpihbp 1-/-mice with triglyceride levels above $2000 \mathrm{mg} / \mathrm{dL}$ but with fenofibrate administration. These findings demonstrated that hypertriglyceridemia subtypes with large TRL particles could affect acute pancreatitis progression and that chylomicrons showed more cytotoxicity than VLDL by releasing more FFAs.
\end{abstract}

Correspondence: Yuhui Wang (wangyuhui2009@bjmu.edu.cn) or Nonghua Lu (lunonghua@ncu.edu.cn)

'Department of Gastroenterology, The First Affiliated Hospital of Nanchang University, 330006 Nanchang, China

${ }^{2}$ Institute of Cardiovascular Sciences, Peking University Health Science Center, 100191 Beijing, China

Full list of author information is available at the end of the article

These authors contributed equally: Yue Zhang, Wenhua He

Edited by A. Stephanou

\section{Introduction}

Hypertriglyceridemia is the cause of acute pancreatitis, and it leads to a poor prognosis ${ }^{1-5}$. However, therapeutic guidelines for hypertriglyceridemia-associated acute pancreatitis are not well established. Triglyceride-lowering treatments have been implemented clinically, but their roles in improving the outcomes of acute pancreatitis remain unclear ${ }^{6-10}$. Therefore, fully understanding the mechanisms of acute pancreatitis under hypertriglyceridemia will be potentially valuable for clinical practice.

\section{(c) The Author(s) 2019}

(c) Open Access This article is licensed under a Creative Commons Attribution 4.0 International License, which permits use, sharing, adaptation, distribution and reproduction cc) in any medium or format, as long as you give appropriate credit to the original author(s) and the source, provide a link to the Creative Commons license, and indicate if changes were made. The images or other third party material in this article are included in the article's Creative Commons license, unless indicated otherwise in a credit line to the material. If material is not included in the article's Creative Commons license and your intended use is not permitted by statutory regulation or exceeds the permitted use, you will need to obtain permission directly from the copyright holder. To view a copy of this license, visit http://creativecommons.org/licenses/by/4.0/. 
The pathogenesis of hypertriglyceridemia is complex and leads to multiple phenotypes enriched with various triglyceride-rich lipoproteins (TRLs) in plasma, including chylomicrons and/or very low-density lipoprotein (VLDL). Hypertriglyceridemia can be mainly divided into three subtypes, namely, Types I, IV, and V hyperlipidemia, according to the plasma TRL composition. It was reported that the subtypes were associated with acute pancreatitis episodes $^{11-14}$ in the clinic, however, their relationship with prognosis and their underlying mechanisms are also worth exploring.

The hyperlipidemia subtypes are the result of interactions between genetic and environmental factors. Genetic mutations associated with lipoprotein lipase activity have been identified as the causes of severe hypertriglyceridemia. We chose two mouse hypertriglyceridemia models to mimic different hypertriglyceridemia subtypes in this study, including glycosylphosphatidylinositol-anchored high-density lipoprotein binding protein 1 knockout (Gpihbp1-/-) and apolipoprotein $\mathrm{C} 3$ transgenic (ApoC3-tg) mice. Gpihbp1 is necessary for TRLs to bind to the vascular endothelium during triglyceride hydrolysis by lipoprotein lipase ${ }^{15,16}$. Gpihbp1 deficiency is one contributing factor to Type I hyperlipidemia with hereditary recurrent acute pancreatitis ${ }^{17-19}$. ApoC3 is involved in the inhibition of TRL hydrolysis and the clearance of their remnants ${ }^{20}$. In some studies performed on human subjects, elevated plasma ApoC3 levels were related to insulin resistance accompanied by hypertriglyceridemia $^{21-23}$. Plasma from the two kinds of mice showed a milky appearance; in Gpihbp1-/- mice, this plasma was mainly enriched with chylomicrons ${ }^{15,16,24}$, whereas in ApoC3-tg mice, it was mainly enriched with VLDL and TRL remnants ${ }^{25,26}$.

Havel, et $\mathrm{al}^{27}$. initially proposed the theory that excessive fatty acids beyond albumin binding can damage the vascular endothelium and pancreatic acinar cells (PACs). Fatty acids in the pancreas are not only derived from lipoproteins but also from peripancreatic adipose tissue, which caused cytotoxicity to PACs mainly due to unsaturated fatty acids but not saturated fatty acids ${ }^{28,29}$ through a variety of mechanisms ${ }^{30-35}$. FFAs are generally considered as an important link between hypertriglyceridemia and acute pancreatitis.

To identify the relationship of hypertriglyceridemia subtypes and acute pancreatitis progression and reveal the underlying mechanisms, we used two kinds of hypertriglyceridemia mouse models with caerulein induction to evaluate the severity of acute pancreatitis, tested the injury of PACs treated with different kinds of TRLs, and examined FFA production and their classifications. We hope our results can explain how both triglyceride levels and the types of TRLs can affect the death of pancreatic acinar cells and thus the severity of acute pancreatitis. These discoveries will help clinicians to develop more precise diagnostic and therapeutic strategies for high-risk patients.

\section{Results \\ Two hypertriglyceridemia mouse models presented different TRL sizes in plasma}

Because the two hypertriglyceridemia mouse models, namely, Gpihbp1-/ - and ApoC3-tg mice, are generated by different genetic modifications, their TRLs may be different when representing the two types of hypertriglyceridemia. We analyzed the characteristics of the TRLs in the plasma from the two models. We found that plasma from Gpihbp1-/- mice had a more milky-white appearance than that from ApoC3-tg mice, although they displayed the same triglyceride levels (Fig. 1a). The optical density was positively associated with the triglyceride concentration in the plasma from both hypertriglyceridemia mice models, while the turbidity (shown as $\mathrm{OD}_{650} /$ triglyceride) of the Gpihbp1-/- mice plasma was significantly higher than the ApoC3-tg mice plasma (Fig. 1b, c). These results suggested that Gpihbp1-/- TRLs may be larger than ApoC3-tg TRLs. For further evidence, we examined their TRLs with transmission electron microscopy, and the results showed much larger TRL particles from Gpihbp1-/- mice than ApoC3-tg mice at the same triglyceride concentration (Fig. 1d); however, there were fewer particles in the Gpihbp1-/- samples than in the ApoC3-tg samples. Additionally, using a Malvern Zetasizer Nano, average and peak sizes of the plasma lipoprotein particles in Gpihbp1-/- mice were identified as significantly larger than those in ApoC3-tg mice (Fig. 1e). Their representative distribution is shown in Supplementary Fig. 1. This evidence suggested that large chylomicron particles are the main TRLs in Gpihbp1-/mice, while small VLDL particles are the main TRLs in ApoC3-tg mice plasma. Therefore, Gpihbp1-/- and ApoC3-tg mice are obviously two different types of hypertriglyceridemia models with different TRL types.

\section{Large areas of pancreatic necrosis were induced in Gpihbp1-/ - mice but not in ApoC3-tg mice by 10 caerulein injections when triglyceride levels were greater than $2000 \mathrm{mg} / \mathrm{dL}$}

We previously found large individual differences in the triglyceride levels in the Gpihbp1-/- and ApoC3-tg mouse models (Supplementary Fig. 2). We chose mice with high triglyceride levels $(>2000 \mathrm{mg} / \mathrm{dL})$ from both models for the induction of acute pancreatitis. There was no significant difference in the triglyceride levels between the Gpihbp1-/- and ApoC3-tg mice (Fig. 2a). However, 


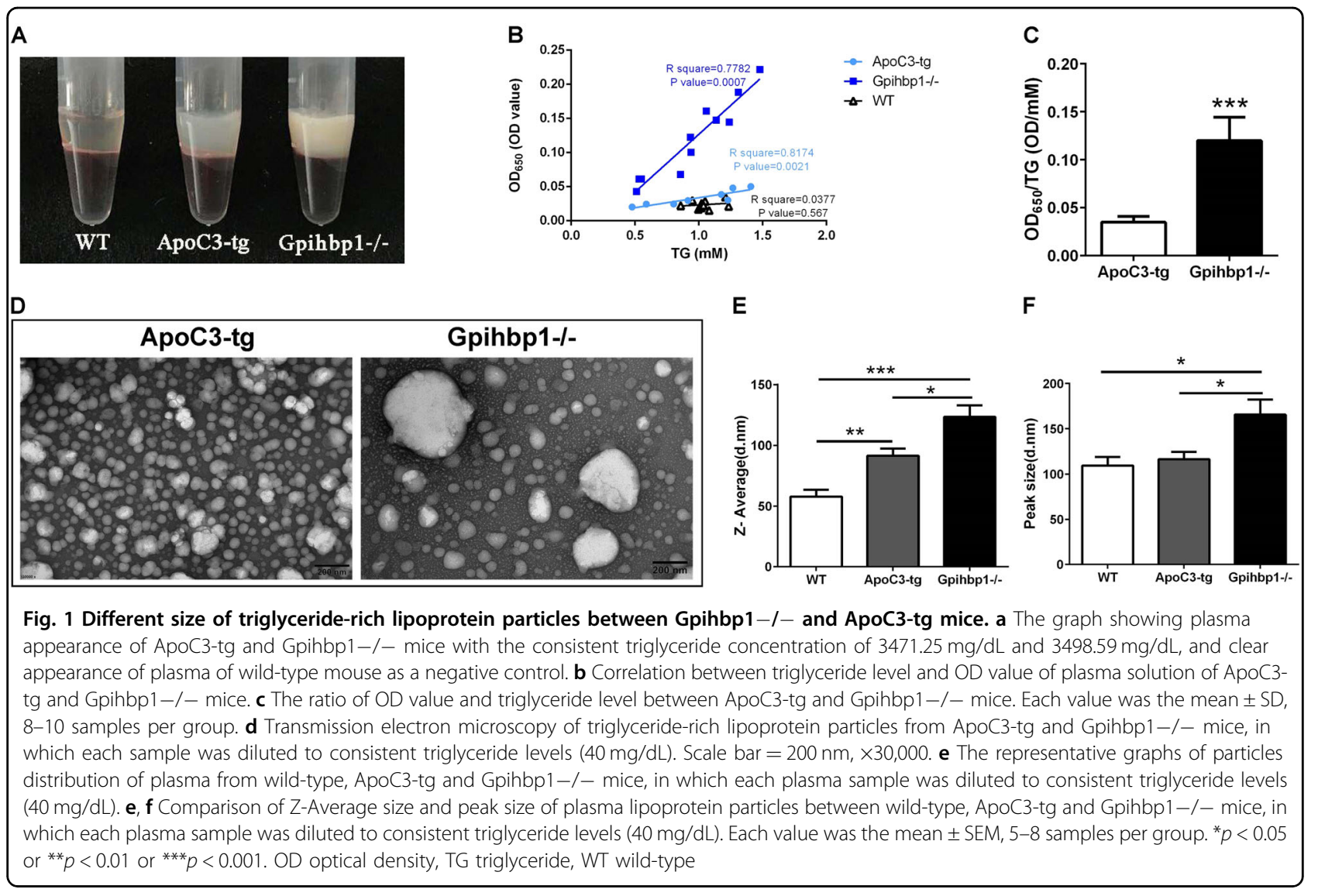

interestingly, the Gpihbp1-/- group showed albescent saponification-like foci in the pancreas (Fig. 2d). Pancreatic cross-sections stained with hematoxylin and eosin (H\&E) showed an exciting result in the Gpihbp1-/group, with large patchy necrotic areas (Fig. 2d and Supplementary Fig. 3) involving pancreatic acini and the surrounding tissues. This was much different from the scattered acinar cell necrosis in the caerulein-induced ApoC3-tg mice and other previous reports on caeruleininduced models ${ }^{3,31,36}$. We defined the pathological features of this patchy necrosis of the whole lobule as pancreatic necrosis compared to the patchy areas of the pancreas without enhancement displayed by contrastenhanced computed tomography in patients. Magnetic renounce imaging also showed that the Gpihbp1-/mouse had many liquid-signal areas, which indicated severe pancreatic injury (Supplementary Fig. 4). Sirius red staining revealed the presence of greater collagen amounts in the necrosis areas (Supplementary Fig. 3). We found that large areas of pancreatic necrosis were absent from both the wild-type and ApoC3-tg groups (Fig. 2f).

The results also showed that amylase and lipase activities were dramatically higher in the caerulein-treatment groups than in the normal saline groups; however, there were no significant differences among the wild-type, ApoC3-tg and Gpihbp1-/- mice in the caeruleintreatment groups (Fig. 2b, c). Because plasma amylase and lipase activities were found to peak at $12 \mathrm{~h}$ after the first caerulein injection in wild-type mice in the pilot study (Supplementary Fig. 5), plasma amylase and lipase activity tests were performed at this time.

Morphologically, compared to the normal saline groups, pancreatic swelling in the caerulein-induced groups was visible from the gross appearance (Fig. 2d). By scoring the $H \& E$-stained sections, we found that edema, inflammatory infiltration, and pancreatic acinar cell necrosis were more severe in the Gpihbp1-/ - group than in the wild-type and ApoC3-tg groups (Fig. 2e). Myeloperoxidase staining showed more neutrophil infiltration in pancreatic tissues from the Gpihbp1-/- group compared to the wild-type and ApoC3-tg groups (Fig. 2g, h), suggesting stronger acute inflammatory response in Gpihbp1-/- group.

When acute pancreatitis caused TRL exposure to pancreatic lipase in pancreatic tissues, triglycerides would be hydrolyzed to release FFAs, resulting in acinar cell damage $\mathrm{e}^{27,28,34,37}$. Via lipid extraction, we found that FFAs in the pancreas were significantly higher in Gpihbp1-/than in ApoC3-tg and wild-type mice after caerulein 


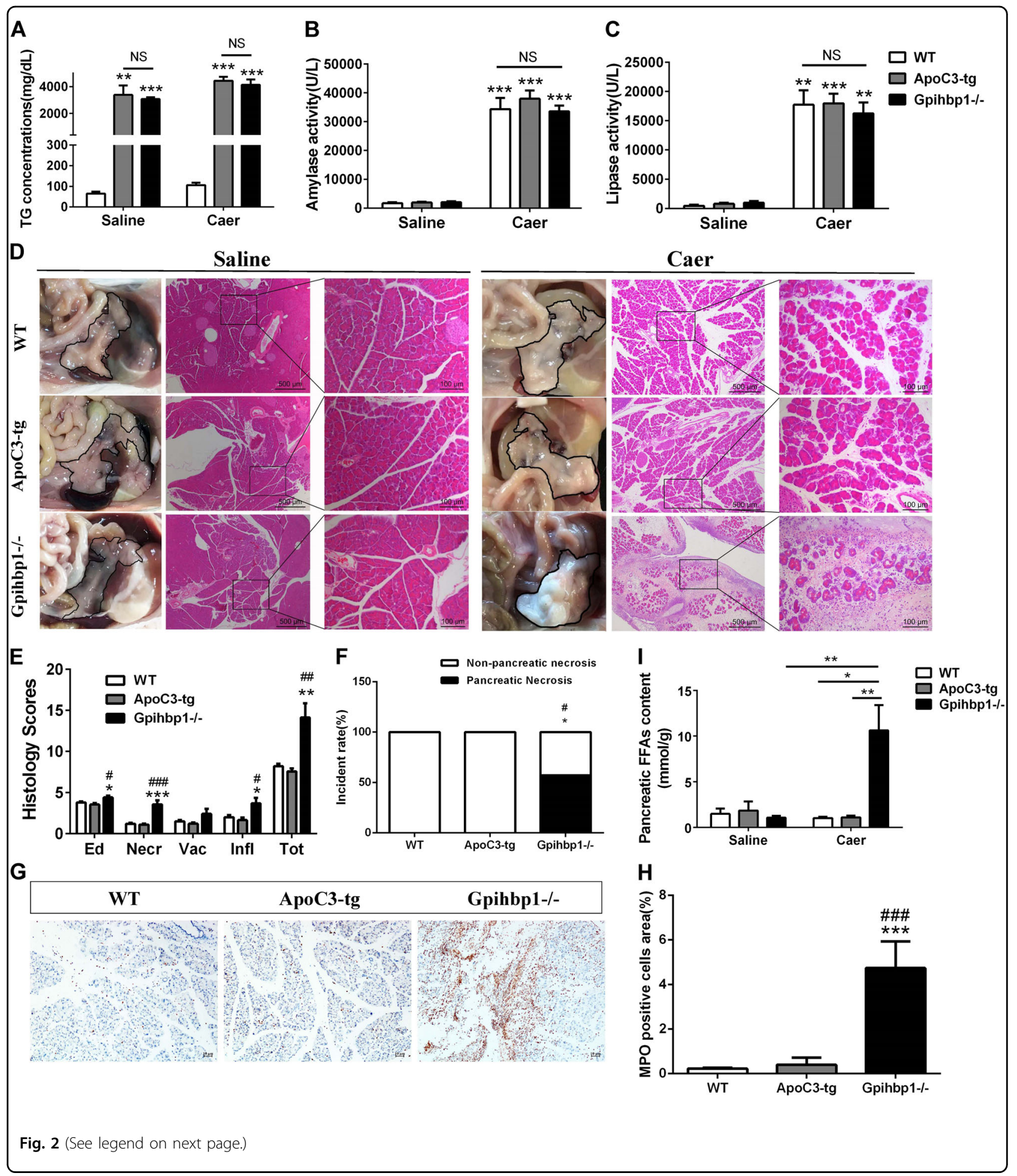

induction, and there were no differences among the three control groups (Fig. 2i). This finding indicated that TRLs in Gpihbp1-/- mice might release large amounts of FFAs locally to further damage the pancreas after acute pancreatitis induction.
ApoC3-tg mice did not develop large areas of pancreatic necrosis even when plasma triglyceride levels increased to levels greater than in Gpihbp1-I- mice

We found that the plasma triglyceride concentration in ApoC3-tg mice decreased by $50 \%$, but not in 
(see figure on previous page)

Fig. 2 The comparison of pancreatic injury, inflammation and free fatty acids of pancreas between wild-type, ApoC3-tg and Gpihbp1-/mice in caerulein-induced acute pancreatitis. a Triglyceride concentration of plasma between wild-type, ApoC3-tg and Gpihbp1-/- mice before caerulein or normal saline treatment. b, c Plasma amylase and lipase activity at 12th hour after the first injection of caerulein between these three groups. Each value was the mean \pm SEM for $n=7-10$ mice in acute pancreatitis groups administrated 10 intraperitoneal injections of caerulein $(50 \mathrm{\mu g} / \mathrm{kg})$ and $n=3-4$ in saline groups administrated equal volume normal saline. d Appearance and representative photomicrographs of H\&Estained section of pancreas of wild-type, ApoC3-tg and Gpihbp1-/- mice in acute pancreatitis groups and normal saline groups. Appearance of pancreas of each sample was delineated with black line. e Pathological scores of the pancreas of wild-type, ApoC3-tg and Gpihbp1-/- mice in acute pancreatitis groups. Scale bar $=500$ or $100 \mu \mathrm{m}$. Each value was the mean \pm SEM for $n=7-10$. $\mathbf{f}$ Incidence rates of pancreatic necrosis of wildtype, ApoC3-tg and Gpihbp1-/- mice in acute pancreatitis groups. $n=7-10 . \mathbf{g}$ Immunohistochemistry evaluation of myeloperoxidase in pancreas of wild-type, ApoC3-tg and Gpihbp1-/- mice in acute pancreatitis groups. Scale bar $=10 \mu \mathrm{m}$. $\mathbf{h}$ Semiquantitative results of the area ratio of myeloperoxidase positive cells among wild-type, ApoC3-tg and Gpihbp1-/- mice in acute pancreatitis groups. Each value was the mean \pm SEM, $n=5$. $\mathbf{i}$ Free fatty acids concentration of pancreas of these three groups in acute pancreatitis groups and normal saline groups. Each value was the mean \pm SEM for $n=5$ in acute pancreatitis groups and $n=3-5$ in normal saline groups. ${ }^{*} p<0.05$ or ${ }^{* *} p<0.01$ or ${ }^{* * *} p<0.001$ vs wild-type group.

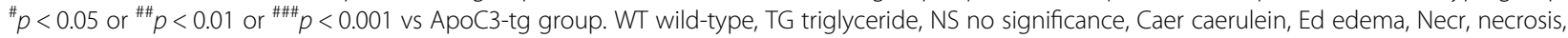
Vac vacuolisation, Infl inflammation, FFAs free fatty acids

Gpihbp1-/ - mice $12 \mathrm{~h}$ after caerulein injection (Supplementary Fig. 6). Therefore, decreased triglyceride levels may lead to less injury without large areas of pancreatic necrosis. We used poloxamer 407 to inhibit the reduction in plasma triglyceride levels during acute pancreatitis ${ }^{36,38}$. The results showed that poloxamer 407 treatment increased plasma triglyceride levels after caerulein injection in ApoC3-tg mice (Fig. 3a) and aggravated pancreatic injury, but large areas of pancreatic necrosis were not induced (Fig. 3b, c). We concluded that the large areas of pancreatic necrosis did not occur regardless of how high the triglyceride levels of small particle TRLs were. Therefore, our results suggested that the particle size, rather than the plasma triglyceride levels, is a key factor for severe pancreatic damage.

\section{TRLs from Gpihbp1-/- mice were more toxic to primary pancreatic acinar cells}

To investigate why mice with large but not small TRL particles can result in severe pancreatic necrosis, we examined the effects of different TRLs on primary pancreatic acinar cells (PACs). First, we found that PACs released lactate dehydrogenase (LDH) in a concentrationdependent manner when they were incubated with Gpihbp1-/- TRLs, but not when incubated with ApoC3tg TRLs, and the LDH concentration was significantly higher with Gpihbp1-/- TRL treatment than ApoC3-tg TRL treatment when the triglyceride concentration was $40 \mathrm{mg} / \mathrm{dL}$ (Fig. 4a). Among these PACs, there was more propidium iodide (PI) uptake by cells and fewer calceinAM-stained cells after treatment with Gpihbp1-/- TRLs than with ApoC3-tg TRLs. (Fig. 4b). Hence, it has been suggested that Gpihbp1-/- TRLs might damage pancreatic acinar cells more than ApoC3-tg TRLs.

Many previous studies have proven that FFAs hydrolyzed from triglycerides were cytotoxic ${ }^{28,31,39}$. In this study, we found that both LDH (activity) and FFAs (concentration) increased more when PACs were incubated with Gpihbp1-/- TRLs than ApoC3-tg TRLs at a TG concentration of $40 \mathrm{mg} / \mathrm{dL}$ (Fig. 4c, d). However, the pancreatic lipase inhibitor orlistat could inhibit the increase in both LDH and FFAs (Fig. 4c, d). When PACs were stimulated with caerulein, both LDH and FFAs increased after incubation with Gpihbp1-/- and ApoC3tg TRLs, though Gpihbp1-/- TRLs still released more LDH and FFAs than ApoC3-tg TRLs (Fig. 4c, d). Trypan Blue staining showed consistent results on PACs damage (Supplementary Fig. 7). Furthermore, when treated with an excess of lipase $(20,000 \mathrm{U} / \mathrm{L})$, FFA production and $\mathrm{LDH}$ release increased to the same level indicated that PACs were equally damaged when incubated with Gpihbp1-/- or ApoC3-tg TRLs (Fig. 4c, d). This finding suggested that different size TRLs have different hydrolysis efficiencies for pancreatic lipase. Gpihbp1-/- TRLs was more liable to releasing FFAs to cause more severe PACs injury than ApoC3-tg TRLs under pathophysiological levels of lipase.

To additionally identify the production of FFAs from different TRLs, we incubated TRLs with lipase (commercial or supernatant from caerulein-stimulated PACs) without PACs. As shown in Fig. 4e, when the lipase activity was up to $20,000 \mathrm{U} / \mathrm{L}$, there were no significant differences in the production of FFAs between TRLs from the Gpihbp1-/ - and ApoC3-tg mice at triglyceride levels of 40 or $20 \mathrm{mg} / \mathrm{dL}$. However, this excess of pancreatic lipase would not present in vivo, regardless of the physiological or pathological state.

However, when TRLs from Gpihbp1-/- or ApoC3-tg mice were incubated with supernatants from caeruleinstimulated PACs (lipase activity at $3565 \pm 223 \mathrm{U} / \mathrm{L}$ ), more FFAs were released from Gpihbp1-/- TRLs than ApoC3tg TRLs (Fig. 4f). Furthermore, we incubated TRLs from Gpihbp1-/- or ApoC3-tg mice with lipase (commercial, gradient activity from 8 to $3200 \mathrm{U} / \mathrm{L}$ ), and we found that more FFAs were released from Gpihbp1-/- TRLs than ApoC3-tg TRLs (Fig. 4g). Thus, these results indicated that 


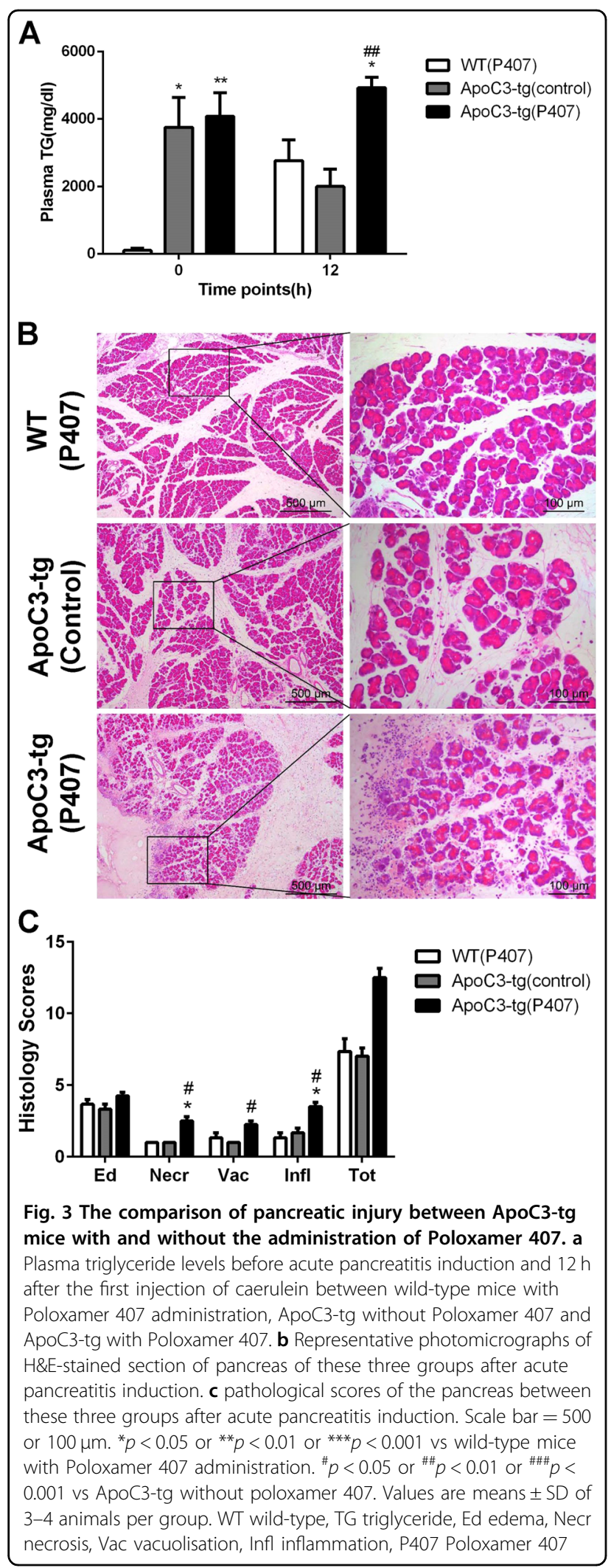

large TRL particles released more FFAs under in vivo lipase activity.

Moreover, to identify whether the FFA compositions of the two types of TRLs were different, which is generally considered as a characteristic of TRLs from different sources, we analyzed the fatty acids compositions of the two TRL types by liquid chromatography mass spectrometry (LC-MS). Higher concentrations of eicosapentaenoic acid (C20:5), docosahexaenoic acid (C22:6, and linoleic acid (C18:2) were found in Gpihbp1-/- TRLs compared to ApoC3-tg TRLs (Supplementary Fig. 8b), which displayed consistent total FFA concentrations (data not shown).

\section{Human chylomicrons were more toxic to primary pancreatic acinar cells than human VLDL}

After identifying that large TRL particles had stronger cytotoxicity to PACs than small TRLs using mouse blood samples, we further investigated whether human TRLs have the same effects as murine TRLs. We separated chylomicrons and VLDL from acute pancreatitis patients with hypertriglyceridemia. PI, Trypan blue and calceinAM staining showed that there were more necrotic PACs after incubation with chylomicrons than VLDL (Fig. 5a, b). Like mouse TRLs, the LDH and FFAs in culture medium with human chylomicrons increased to greater than that with VLDL. (Fig. 5c, d).

\section{Lowering plasma triglycerides in Gpihbp1-I- mice with large TRL particles significantly reduced pancreatic necrosis}

As described in the Supplementary Fig. 2, because of the individual differences in Gpihbp1-/- mice triglyceride levels, we chose individuals with triglyceride levels greater than $2000 \mathrm{mg} / \mathrm{dL}$ for the experiments above. Here, to investigate the relationship of triglyceride levels and the incidences of large areas of pancreatic necrosis in Gpihbp1-/- mice with large TRL particle sizes, we compared low triglyceride level Gpihbp1-/- mice $(<2000 \mathrm{mg} / \mathrm{dL}, \mathrm{HTG} 1)$ with high triglyceride level mice $(>2000 \mathrm{mg} / \mathrm{dL}, \mathrm{HTG} 2)$ on the severity of acute pancreatitis (Fig. 6a). After caerulein induction, both amylase and lipase activities were not significantly different among the wild-type, HTG1 and HTG2 groups (Fig. 6b, c). Morphologically, the HTG1 group showed more severe pancreatic injury than the wild-type mice but considerably less pancreatic damage than the HTG2 mice (Fig. 6d, e). The incidence rate of pancreatic necrosis was $100 \%$ in the HTG2 group, while the incidence rate was $0 \%$ in the wildtype group and $17 \%$ in the HTG1 group (Fig. 6f). More myeloperoxidase and CD68-positive cells were found in 

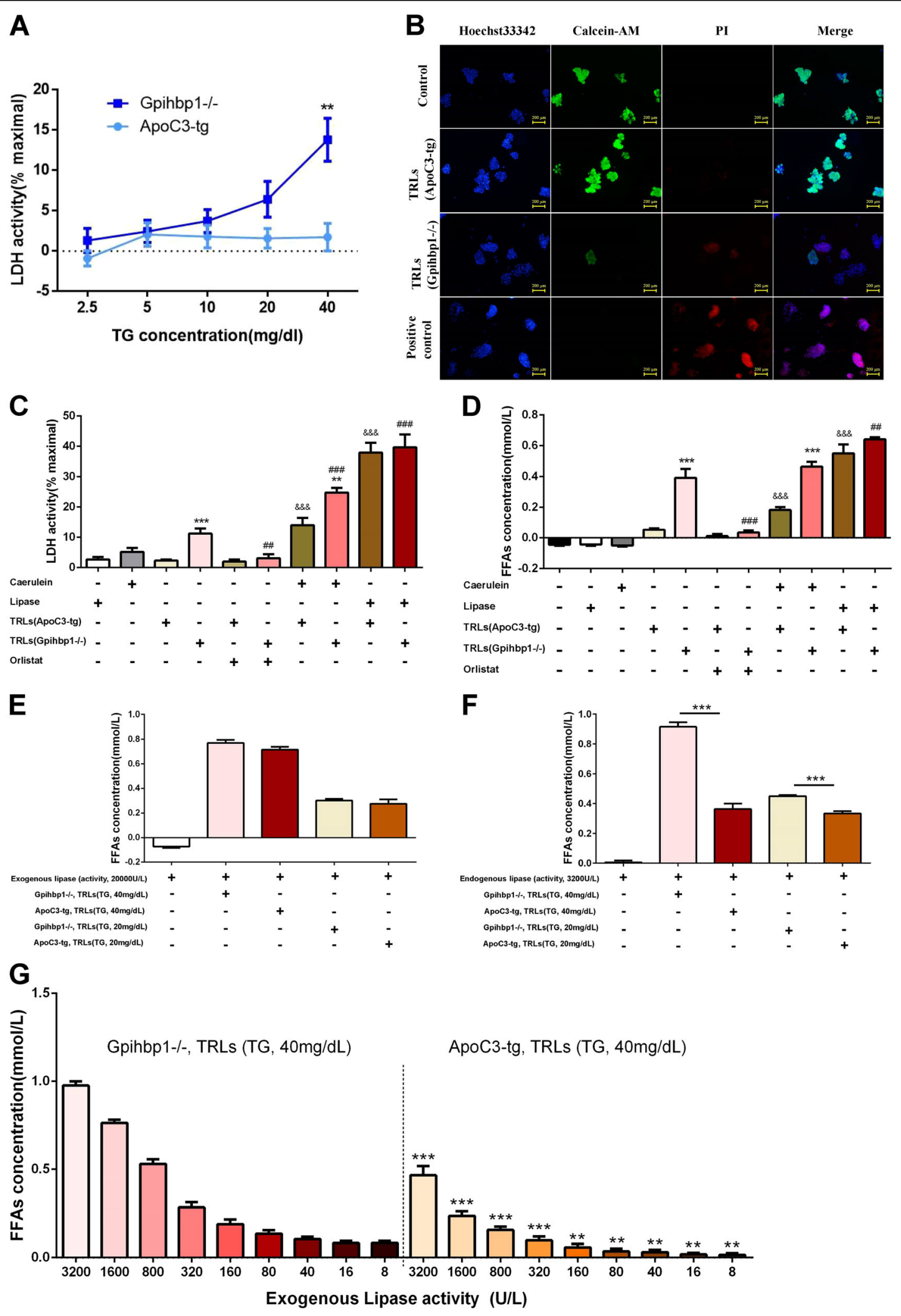

Fig. 4 (See legend on next page.) 
(see figure on previous page)

Fig. 4 The comparison of cytotoxicity to primary pancreatic acinar cells between triglyceride-rich lipoproteins from Gpihbp1-/- and ApoC3-tg mice. a Cell necrosis was quantified as \% lactate dehydrogenase leakage after primary pancreatic acinar cells being incubated for 30 min with triglyceride-rich lipoproteins from Gpihbp1-/- and ApoC3-tg mice when triglyceride concentrations of TRLs were 2.5, 5, 10, 20, 40 mg/dL, respectively. ${ }^{*} p<0.05$ or ${ }^{* *} p<0.01$ or ${ }^{* * *} p<0.001$ vs ApoC3-tg group. Three samples for each group for two independent experiments. $\mathbf{b}$ Representative graphs of Hoechst33342, PI and calcein-AM fluorescence staining of primary pancreatic acinar cells after incubated with triglyceriderich lipoproteins from ApoC3-tg and Gpihbp1-/- mice with triglyceride concentration of $40 \mathrm{mg} / \mathrm{dL}$ for $30 \mathrm{~min}$. Scale bar $=200 \mu \mathrm{m}$. c Percent Lactate dehydrogenase leakage, $\mathbf{d}$ Levels of free fatty acids when primary pancreatic acinar cells were incubated with caerulein, lipase, triglyceriderich lipoproteins of ApoC3-tg and Gpihbp1-1- mice with triglyceride concentration of $40 \mathrm{mg} / \mathrm{dL}$ alone or accompanied with caerulein or orlistat or lipase for $30 \mathrm{~min}$. Scale bar $=200 \mu \mathrm{m}$. Three samples for each group for two independent experiments. ${ }^{*} p<0.05$ or ${ }^{* *} p<0.01$ or ${ }^{* * *} p<0.001 \mathrm{TRLS}$ (Gpihbp1-/-) group vs TRLs (ApoC3-tg) group or TRLs (Gpihbp1-/-) + caerulein group vs TRLs(ApoC3-tg) + caerulein group. " $p<0.05$ or \#\# $p<$

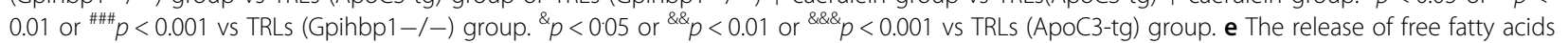
when triglyceride-rich lipoproteins (triglyceride concentration, $40 \mathrm{mg} / \mathrm{dL}$ or $20 \mathrm{mg} / \mathrm{dL}$ ) from ApoC3-tg and Gpihbp1-/- mice was incubated with pig pancreatic lipase (lipase activity, about 20,000 U/L) for $30 \mathrm{~min}$. $\mathbf{f}$ The release of free fatty acids when triglyceride-rich lipoproteins (triglyceride concentration, $40 \mathrm{mg} / \mathrm{dL}$ or $20 \mathrm{mg} / \mathrm{dL}$ ) from ApoC3-tg and Gpihbp1-/- mice was incubated with supernatant (lipase activity, about $3000 \mathrm{U} / \mathrm{L}$ ) collected through primary pancreatic acinar cells incubated with caerulein $(100 \mathrm{nM})$ for $30 \mathrm{mins}$. $\mathbf{g}$ The release of free fatty acids when triglyceriderich lipoproteins from ApoC3-tg and Gpihbp1-/- mice with triglyceride level of $40 \mathrm{mg} / \mathrm{dL}$ was incubated with various activity of pig pancreatic lipase for 30 min. ${ }^{*} p<0.05$ or ${ }^{* *} p<0.01$ or ${ }^{* * *} p<0.001$ vs Gpihbp $1-/-$ with corresponding lipase activity. Three samples for each group for two independent experiments. PI propidium iodide, FFAs free fatty acids, TRLs triglyceride-rich lipoproteins, LDH lactate dehydrogenase

pancreatic tissues from the HTG2 group than the wildtype and HTG1 groups (Fig. 6g-i). Interleukin $1 \beta$ (IL-1 $1 \beta$ ) and monocyte chemotactic protein 1 (MCP-1) mRNA expression in the pancreas was significantly higher in the HTG2 group than in the HTG1 and wild-type groups; mRNA expression of vascular cell adhesion molecule-1 (VCAM-1) was higher in the HTG1 group than in wildtype group (Supplementary Fig. 9).

We lowered the plasma triglyceride concentration by fenofibrate administration to investigate the preventive effects on acute pancreatitis exacerbation in Gpihbp1-/mice. We found that plasma triglyceride concentrations were dramatically lowered in Gpihbp1-/- mice after 6 days of fenofibrate administration before acute pancreatitis was induced (Fig. 7a). On the seventh day, when triglyceride levels were stable at low levels (487.4 \pm $353.3 \mathrm{mg} / \mathrm{dL}$ ) due to fenofibrate treatment, we induced acute pancreatitis by caerulein injection. We found that Gpihbp1-/- mice with fenofibrate treatment showed a reduced incidence of pancreatic necrosis and injury by H\&E staining (Fig. 7b-d).

\section{Discussion}

It is well known that patients with type I hyperchylomicronemia exhibit extremely higher acute pancreatitis episodes than patients with types IV (hyperpre$\beta$-lipoproteinemia) and $\mathrm{V}$ (mixed type hyperpre$\beta$-lipoproteinemia and chylomicronemia) hyperlipide$\mathrm{mia}^{13}$. It has also been reported that among Chinese patients, variants of lipoprotein lipase or its regulating genes, which have been linked with hyperchylomicronemia, increased the risk of acute pancreatitis ${ }^{40}$. Therefore, clinical practices have revealed that chylomicrons have a close relationship with acute pancreatitis.
In this study, two kinds of hypertriglyceridemia mouse models allowed us to compare the effects of different kinds of TRLs on the exacerbation of acute pancreatitis, and the large areas of pancreatic necrosis induced by 10 caerulein injections in Gpihbp1-/- mice allowed us to examine the special effects of large TRL particles almost at a glance. Gpihbp1-/- mice showed very high plasma triglyceride levels because of the almost complete deficiency in lipoprotein lipase function, resulting in chylomicronemia ${ }^{17}$. ApoC3 overexpression results in increased VLDL and remnants by inhibiting lipoprotein lipase activity and remnants clearance and promoting VLDL synthesis ${ }^{20}$. Different genetic modifications can lead to different TRL metabolism disorders and the presence of larger TRL particles in Gpihbp1-/- than those in ApoC3-tg. Our results showed that even with the same high triglyceride levels, pancreatic injury exacerbation and the presence of large areas of pancreatic necrosis only occurred in Gpihbp1-/- mice, not in ApoC3-tg mice. Moreover, poloxamer 407 treatment in ApoC3-tg mice further increased triglyceride levels, but did not to induce large areas of pancreatic necrosis in this type of hypertriglyceridemia. This phenomenon is very similar to the inconsistent prognosis of acute pancreatitis in patients even though they have the same high triglyceride levels. Additionally, we were excited to find that the very severe necrosis associated with large patchy pancreatic parenchymal tissues mimicking patients could be induced in Gpihbp1-/- mice. We considered that animal models and patients with hypertriglyceridemia may have the same mechanisms for the aggravation of acute pancreatitis. Our results showed that the hypertriglyceridemia subtype is a key factor during this process due to the different types of TRLs damaging PACs differently. 


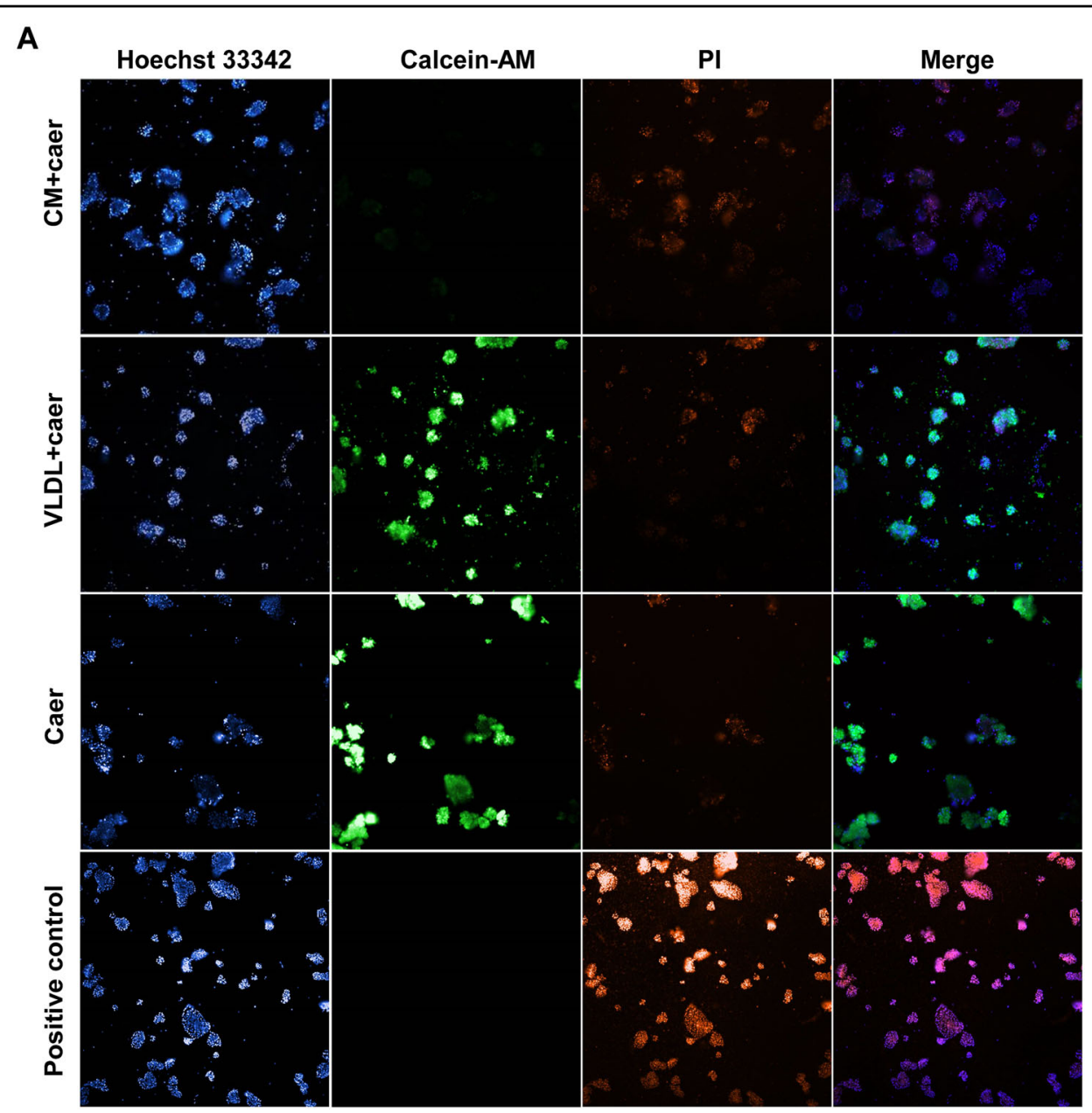

B
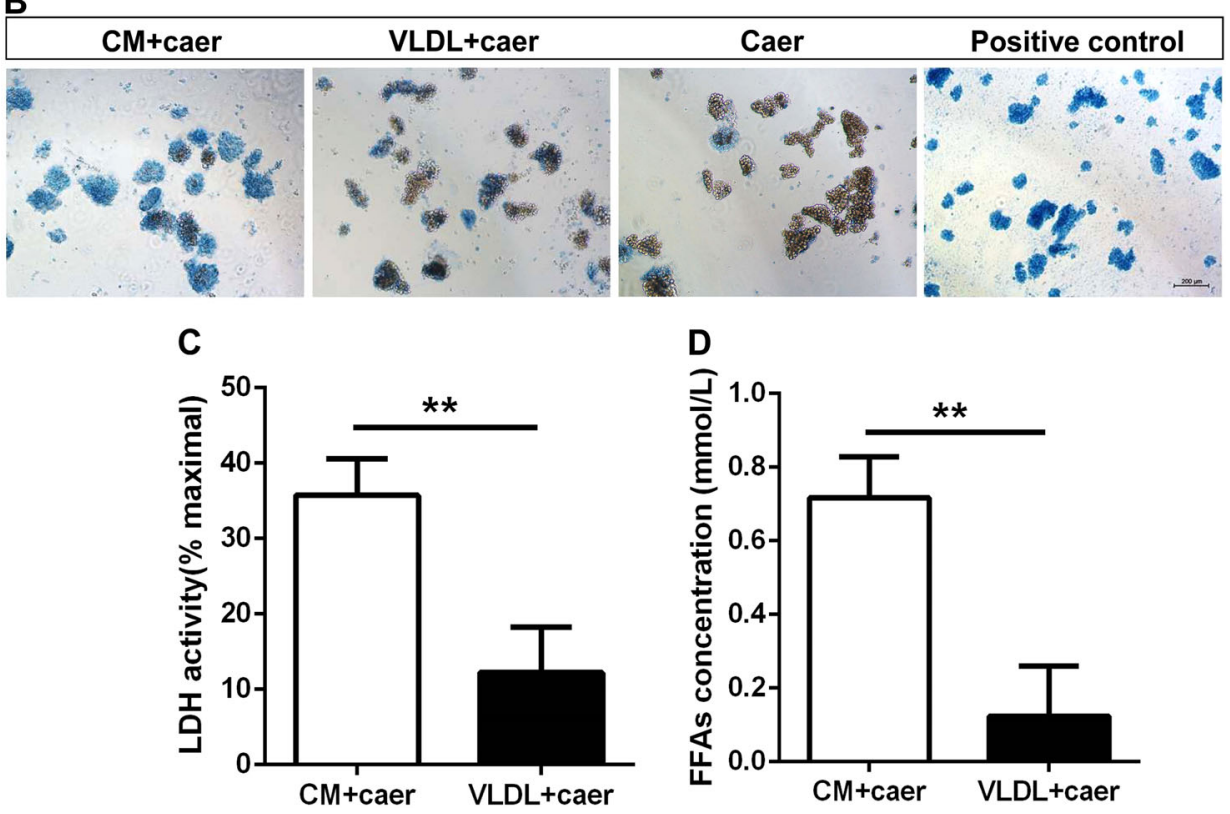

Fig. 5 (See legend on next page.) 
(see figure on previous page)

Fig. 5 The comparison of cytotoxicity to primary pancreatic acinar cells between chylomicron and very low-density lipoprotein from acute pancreatitis patients with hypertriglyceridemia. a Representative graphs of Hoechst33342, PI and calcein-AM fluorescence staining of primary pancreatic acinar cells after incubated with caerulein (100 nM) combining chylomicron or very low-density lipoprotein with triglyceride concentration of $40 \mathrm{mg} / \mathrm{dL}$ for $30 \mathrm{~min}$. Photographed by high-throughput cell imaging system, Scale bar $=100 \mu \mathrm{m}$. b Representative graphs of Trypan Blue Dye of primary pancreatic acinar cells when they were incubated with caerulein (100 nM) combining chylomicron or very low-density lipoprotein with triglyceride concentration of $40 \mathrm{mg} / \mathrm{dL}$ for $30 \mathrm{~min}$. Scale bar $=200 \mu \mathrm{m}$. c, d Lactate dehydrogenase leakage $\%$ and free fatty acids concentration when primary pancreatic acinar cells were incubated with caerulein $(100 \mathrm{nM})$ combining chylomicron or very low-density lipoprotein with triglyceride concentration of $40 \mathrm{mg} / \mathrm{dL}$ for $30 \mathrm{~min}$. ${ }^{*} p<0.05$ or ${ }^{* *} p<0.01$ or ${ }^{* * *} p<0.001$. Three samples for each group. PI propidium iodide, CM chylomicron, VLDL very low-density lipoprotein, LDH lactate dehydrogenase, FFAs free fatty acids

At present, some studies have shown that FFAs, hydrolysis products of TRLs, play a key role in hypertriglyceridemia-related pancreatic injury ${ }^{28,30}$. In our study, more FFAs were extracted from the pancreas of Gpihbp1-/ - mice than ApoC3-tg mice after caerulein induction, suggesting that greater FFA production may be the reason for occurrence of pancreatic necrosis in Gpihbp1-/ - mice. In in vitro experiments, more FFAs were released and more cytotoxicity was directed towards PACs from Gpihbp1-/- TRLs than ApoC3-tg TRLs, which was consistent with quantities of FFAs produced in vivo. This further confirmed that these pathological processes were important during the progression of hypertriglyceridemia-associated acute pancreatitis. Our results also showed that TRLs were the substrates of pancreatic lipase. Additionally, under an in vivo environment, the activity of pathologically released pancreatic lipase can promote more hydrolysis of large TRLs particles (chylomicrons). Taken together, these results suggested that large TRL particles may release more FFAs than small TRL particles in response to pancreatic lipase.

However, future research should examine the manners by which pancreatic lipase affects TRLs, such as its enzymatic kinetics and coproteins or other auxiliaries. Although ApoC3 can inhibit lipoprotein lipase activity, it remains unclear whether ApoC3 overexpression also inhibit pancreatic lipase activity, resulting in less FFA release. Moreover, whether other lipoprotein lipase activity suppressor genes can also influence pancreatic lipase activity also needs to by confirm.

The increased FFAs hydrolyzed from large TRL particles locally in pancreatic tissue might be the reason for the increased severe pancreas injury until the presence of pancreatic necrosis through a vicious circle in Gpihbp1 -/- mice due to large TRL particles. Chylomicrons separated from patient plasma released more FFAs and showed stronger cytotoxic effects on PACs than VLDL, suggesting to some extent that this mechanism also occurs in humans.

In addition, we also found more unsaturated fatty acids in TRLs from Gpihbp1-/- than from ApoC3-tg mice (Supplementary Fig. 8b). Unsaturated fatty acids are dietary-derived, essential fatty acids for mammals ${ }^{41,42}$.
This result also explained that TRLs in Gpihbp1-/- mice were mainly enriched in chylomicrons of intestinal origin. Moreover, it has been reported that unsaturated fatty acids rather than saturated fatty acids caused more damage to PACs ${ }^{28,39}$. Therefore, more unsaturated fatty acids in TRLs may be another reason for the exacerbation and occurrence of pancreatic necrosis in acute pancreatitis.

Orlistat was effective at inhibiting pancreatic lipase activity in vitro, in animal experiments, triglyceridelowering treatment significantly reduced the severity of acute pancreatitis and pancreatic necrosis. In clinical practice, necrotizing pancreatitis involve pancreatic parenchymal necrosis, extra-pancreatic necrosis or their combination, whereby patients with pancreatic parenchymal necrosis alone or in combination more often suffered from systemic and local complications ${ }^{43-50}$. Due to the lack of guidance for the treatment of acute pancreatitis with hypertriglyceridemia, the National Association for the Improvement of Blood (ASFA) only classifies these patients as a Class III indication for plasma exchange, which can be used individually ${ }^{51}$. Our results suggested that hypertriglyceridemia-associated acute pancreatitis prognosis should refer to the hypertriglyceridemia subtype and particle size, and severe acute pancreatitis caused by extensive pancreatic necrosis should be prevented by lowering triglyceride levels which potentially decrease large TRL particles. This study suggested that patients with elevated chylomicrons would be more likely to benefit from emergency lipid-lowering therapy, which requires the performance of future clinical studies to confirm. Additionally, our findings also propose a potential value for the development of methods to remove chylomicrons but not VLDL.

The study also suggested that inhibition of FFA production may be an effective way to inhibit pancreatic acinar cell injury. However, orlistat, a lipase inhibitor, fails to enter the pancreatic vascular bed and extracellular space of pancreatic acinar cells through blood circulation due to its insolubility.

In summary, a severe necrotic pancreatitis mouse model with hypertriglyceridemia by caerulein induction was established in this study. In future, many studies on 


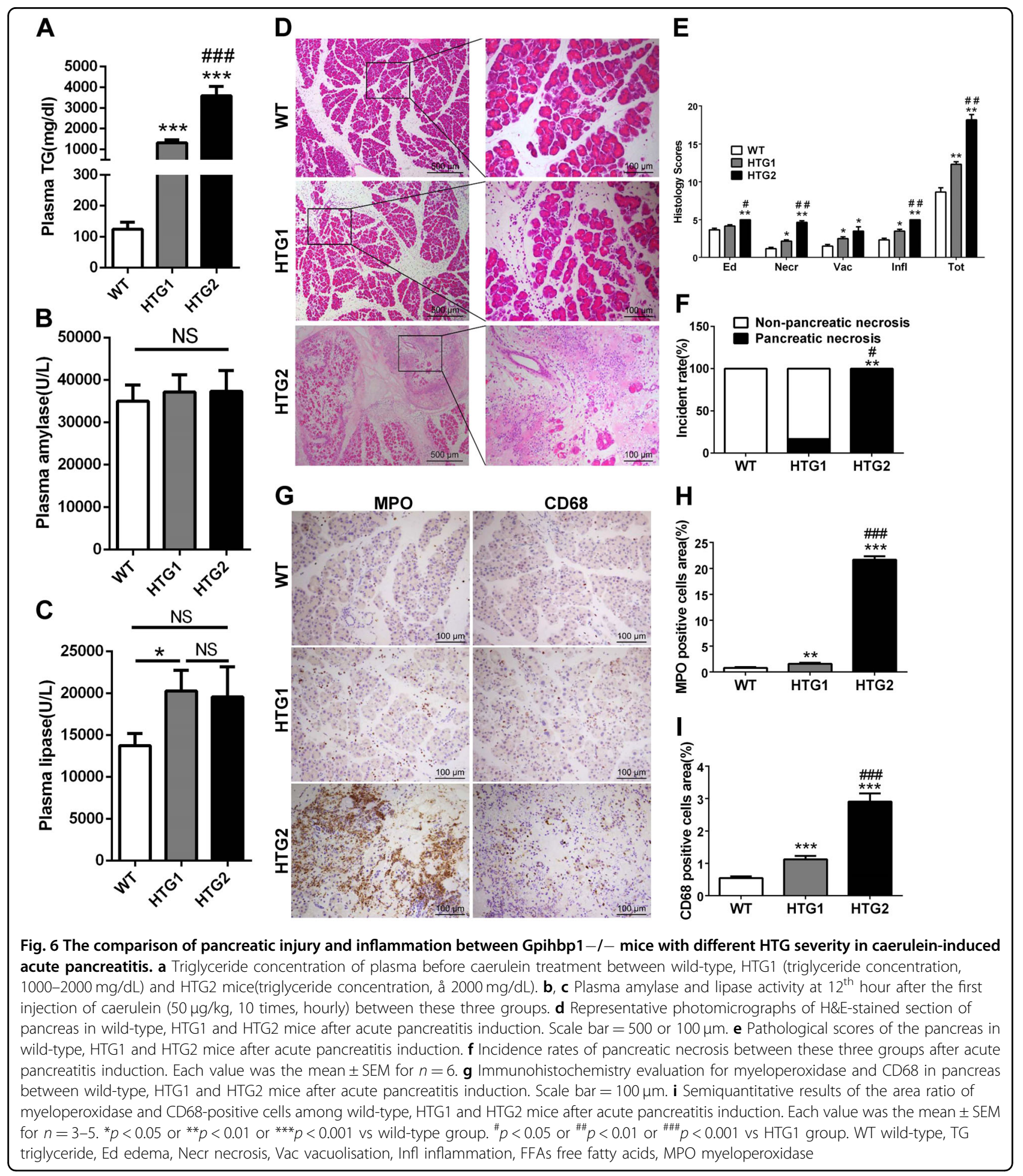

mechanisms or preventive treatments for acute pancreatitis with hypertriglyceridemia could be performed on this animal model. We here by this model, we found that both triglyceride levels and the TRL composition are the key factors for the development of acute pancreatitis, especially pancreatic necrosis. Triglycerides derived from large TRL particles, such as chylomicrons, rather than small TRL particles, might be more harmful to the pancreas after the onset of acute pancreatitis. 


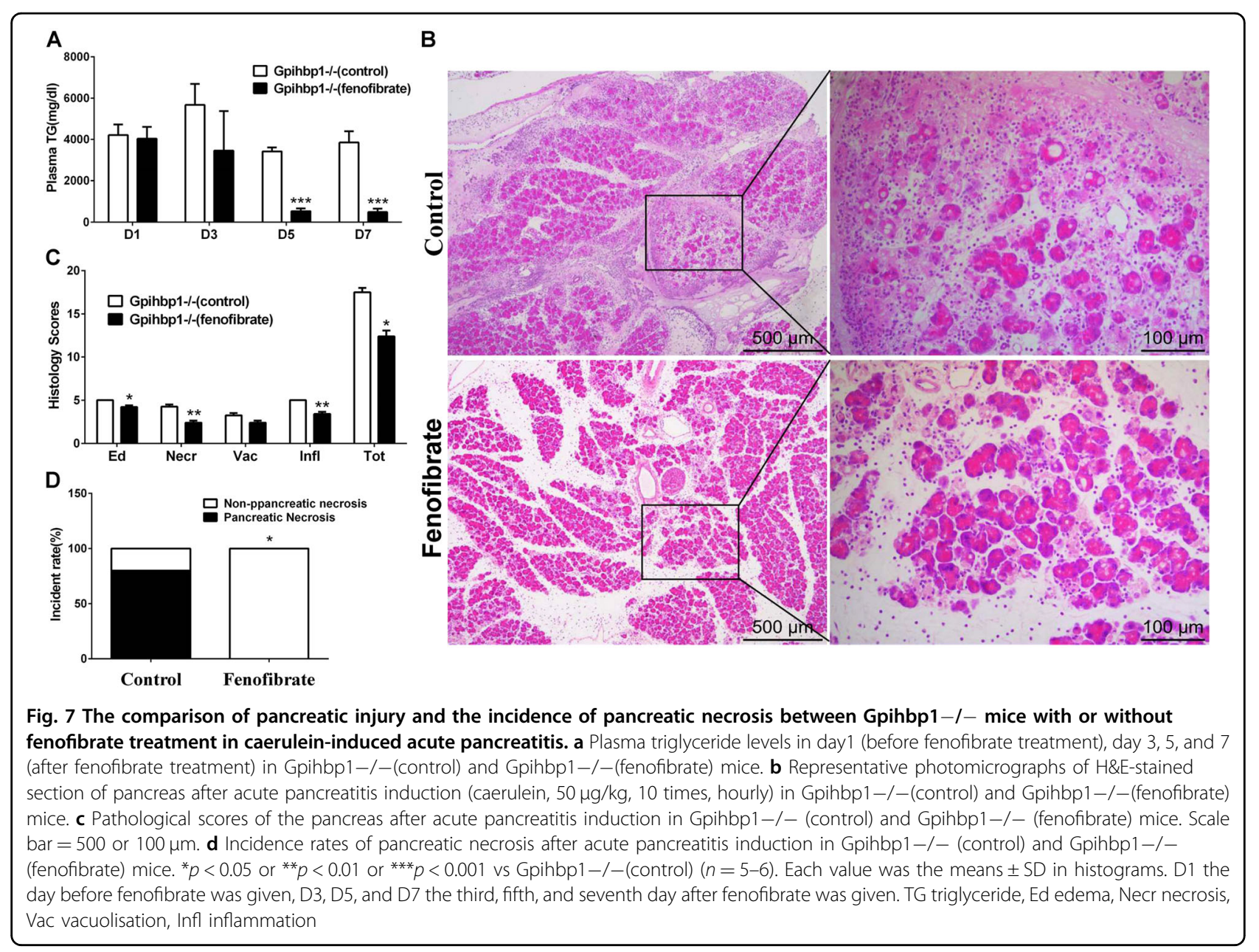

\section{Materials and methods \\ Animal experiments}

In this study, Gpihbp1-/- mice with a C57BL/6 background were obtained from MMRRC Mice Services (strain name: B6;129S5-Gpihbp1tm1Lex/Mmucd; stock no. 032334-UCD) and human ApoCIII transgenic mice with a C57BL/6 background were obtained from JAX Mice Services (strain name: B6; CBA-Tg [APOC3] 3707Bres/J; stock no. 006907) through a Chinese agent (Vital River Laboratories, Beijing, China) at the Institute of Cardiovascular Sciences of Peking University (Beijing, China). Because we had previously found that CD1 mice were more sensitive to caerulein induction ${ }^{52}$, in this study, both Gpihbp1-/- and ApoC3-tg mice with a C57BL/6 background were crossbred with CD1 background mice for seven generations to generate their CD1 lines for our experiments.

Genotyping of Gpihbp1-/- and ApoC3-tg mice was performed by PCR analysis of genomic DNA extracted from their tails ${ }^{53}$. Female and male mice aged 10-15 weeks and weighting $\sim 32-38$ g were used in this study. Animals were maintained under a 12-h light/12-h dark cycle at $24{ }^{\circ} \mathrm{C}$ with standard laboratory chow and water ad libitum. The Principles of Laboratory Animal Care (NIH publication no. 85Y23, revised 1996) were upheld during the study. All experiments were performed in accordance with protocols approved by the Animal Care Committee, Peking University Health Science Center (LA2015012). Experiments were also approved by the Institutional Animal Care and Use Committee of Nanchang University and followed the rules set forth in the Guide for the Care and Use of Laboratory Animals.

For evaluating how the hypertriglyceridemia subtypes affected the progress of acute pancreatitis, mice were divided into experimental groups for acute pancreatitis induction and control groups for normal saline treatment, with both consisting of the following three groups: wildtype group (normal plasma triglyceride levels), ApoC3-tg (hypertriglyceridemia model), and Gpihbp1-/- (hypertriglyceridemia model) groups. The two kinds of hypertriglyceridemia mice with similar triglyceride levels (greater than $2000 \mathrm{mg} / \mathrm{dL}$ ) were selected for the induction of acute pancreatitis to compare their pancreatic injuries. 
Poloxamer 407 is a hydrophilic triblock copolymer comprised of polyoxyethylene and polyoxypropylene units and has been reported to induce hypertriglyceridemia with few side effects ${ }^{54}$. Poloxamer 407 can increase serum triglyceride concentrations up to $2000 \mathrm{mg} / \mathrm{dL}$ by directly inhibiting the activity of both lipoprotein lipase and hepatic lipase $\mathrm{s}^{55-57}$. A previous study showed that poloxamer 407 could be used long-term in wild-type mice to establish hypertriglyceridemia mice for research on acute pancreatitis $^{36}$. In our study, we used poloxamer 407 once to transiently increase triglyceride levels in ApoC3-tg mice during acute pancreatitis induction. Furthermore, to identify whether increasing triglyceride levels in ApoC3-tg mice during acute pancreatitis induction could exacerbate pancreatic injury, ApoC3-tg mice with triglyceride levels greater than $2000 \mathrm{mg} / \mathrm{dL}$ after poloxamer 407 treatment were compared with ApoC3-tg mice without poloxamer 407 after acute pancreatitis induction. The wild-type mice treated with poloxamer 407 in this experiment were designed to exclude the effects of poloxamer 407 administration on pancreatic injury compared to further increasing plasma triglycerides during acute pancreatitis induction in ApoC3-tg mice.

To understand how triglyceride levels in the Gpihbp1-/mouse model affected the progression of acute pancreatitis, Gpihbp1-/- mice were divided into the HTG1 group (Gpihbp1-/- mice with triglyceride levels greater than $1000 \mathrm{mg} / \mathrm{dL}$ and less than $2000 \mathrm{mg} / \mathrm{dL}$ ) and HTG2 group (Gpihbp1-/- mice with triglyceride levels greater than $2000 \mathrm{mg} / \mathrm{dL}$ ). Wild-type mice with normal triglyceride levels were considered as controls. Then, acute pancreatitis was induced in these groups. Moreover, for further evidence, Gpihbp1-/- mice with triglyceride levels greater than $2000 \mathrm{mg} / \mathrm{dL}$ were treated with fenofibrate until their plasma triglycerides decreased to a stable low level as well as solvent as a control. Then, acute pancreatitis was induced in the two groups to verify whether dramatically decreasing plasma triglyceride levels in Gpihbp1-/- mice with triglyceride levels greater than $2000 \mathrm{mg} / \mathrm{dL}$ could prevent pancreatic injury.

\section{Induction of acute pancreatitis and sample collection}

Because patients are usually attacked by acute pancreatitis after eating, in this study, all mice were fed chow diets and water ad libitum before the induction of acute pancreatitis. A sterile solution of caerulein (AnaSpec, Inc., Fremont, USA) was prepared in normal saline at a concentration of $10 \mu \mathrm{g} / \mathrm{ml}$ and administered intraperitoneally to induce acute pancreatitis by 10 hourly injections at $50 \mu \mathrm{g} / \mathrm{kg}$ body weight. Equivalent normal saline was injected as a non-acute pancreatitis control.

Poloxamer 407 (Sigma) was intraperitoneally injected into ApoC3-tg mice at $200 \mathrm{mg} / \mathrm{kg}$; the two control groups were ApoC3-tg mice without poloxamer 407 treatment and wild-type mice with poloxamer 407 treatment $(200 \mathrm{mg} / \mathrm{kg})$. Poloxamer 407 was administered half an hour after the first caerulein injection.

Fenofibrate (Recipharm Fournier, France) in 0.5\% carboxymethyl cellulose sodium (CMC-Na) at $100 \mathrm{mg} / \mathrm{kg}$ body weight was administered by intragastric infusion three times per day for several days. Caerulein-induced acute pancreatitis was promoted until plasma triglycerides decreased to a stable low level in the fenofibrate treatment group.

Blood samples were collected from the orbital vein with heparin sodium for anticoagulation at 0,12 , and $24 \mathrm{~h}$ after the first caerulein injection. Plasma was isolated by centrifugation at $4000 \mathrm{rpm}$ for $10 \mathrm{~min}$ at $4{ }^{\circ} \mathrm{C}$. Mice were sacrificed by overdose with pentobarbital (Fort Dodge Animal Health, Fort Dodge, Iowa, USA) at $24 \mathrm{~h}$ after the first caerulein injection. Part of the pancreas was fixed in $4 \%$ buffered paraformaldehyde for paraffin sectioning and the other part was frozen in $-80^{\circ} \mathrm{C}$ for mRNA and lipid extraction.

\section{Biochemistry assay}

In this study, plasma triglyceride levels were measured by the enzymatic terminal method using commercial kits (Biosino Biotechnology and Science Inc, Beijing, China). The FFA concentrations were also examined by commercial kits (Wako LabAssay, Japan) as described in their manuals. Amylase and lipase activities were measured by the Catalyst Dx Chemistry Analyzer (IDEXX Laboratories, Inc., Westbrook, ME) using the DRI-CHEM method. Plasma samples for amylase and lipase tests were preprocessed by ultracentrifugation at $25,000 \mathrm{rpm}$ for $30 \mathrm{~min}$ at $4{ }^{\circ} \mathrm{C}$ to avoid lipemia interference. Amylase and lipase activities were tested from plasma collected at $12 \mathrm{~h}$ after the first caerulein injection using the premise that their activities in mice plasma reached a peak in the $12 \mathrm{~h}$ after the first caerulein injection (Supplementary Fig. 5). The lactic dehydrogenase (LDH) activity of cell culture medium was measured using a commercial kit via a $30 \mathrm{~min}$ reaction at room temperature in the dark (Dojindo, Japan).

\section{Histopathological assay}

Paraffin-embedded pancreatic tissue was cut into 4- $\mu \mathrm{m}$ sections for H\&E and Sirius Red staining by usual methods. Two investigators were blinded to evaluate the severity of edema, inflammation, necrosis, and vacuolization according to previously described standards in the H\&E staining image analysis ${ }^{58,59}$, in which the evaluation of necrosis was modified to sensitively discriminate the degree of necrosis (Supplementary Table 1). The incidence rate of pancreatic necrosis was calculated by the ratio of the number of mice with large areas of necrosis to the total number of mice within the same treatment 
group. Neutrophil and macrophage infiltration were evaluated by immunohistochemical staining using antimyeloperoxidase rabbit polyclonal antibody (Abcam, ab9535) and anti-CD68 rabbit polyclonal antibody (Boster, BA3638), respectively. Briefly, paraffin-embedded sections were deparaffinized and incubated with $0.3 \%$ $\mathrm{H}_{2} \mathrm{O}_{2}$ solution to remove endogenous peroxidase activity. Antigen retrieval was performed with citrate buffer $(\mathrm{pH}$ 6.8). Then, goat serum was used to block nonspecific antigens. The sections were incubated with diluted (1:200) anti- myeloperoxidase polyclonal antibody or diluted (1:400) anti-CD68 polyclonal antibody. The secondary antibody was a goat anti-rabbit secondary antibody. A diaminobenzene horseradish peroxidase color development kit was used for stain development. The sections were counterstained with hematoxylin and dehydrated. The myeloperoxidase areas and CD68-positive cells were calculated using the ImageJ software.

\section{Quantitative PCR assay}

Total RNA from pancreatic tissues was extracted with the Trigol Reagent (Dingguo Biotechnology Limited Company, Beijing, China). Gel electrophoresis was performed to confirm no degradation after reverse transcription with Super Script II RT (Invitrogen, Carlsbad, Calif). Inflammatory cytokine expression was quantified by quantitative PCR with EVA Green (Invitrogen, Carlsbad, Calif). The expression of the tested genes was normalized to glyceraldehyde-phosphate dehydrogenase $(\mathrm{GAPDH})$ expression. The primer sequences are as follows:

IL-1 $\beta$,

forward-GCCACCTTTTGACAGTGATGAG and reverse-AAGGTCCACGGGAAAGACAC; CCCL2/MCP1, forward-CCACAACCACCTCAAGCACT and reverse-TAAGGCATCACAGTCCGAGTC; VCAM-1, forward-AGTTGGGGATTCGGTTGTTCT and reverse-CCCCTCATTCCTTACCACCC; and GAPDH,

forward-TGATGACATCAAGAAGGTGGTGAAG and reverse-TCCTTGGAGGCCATGTAGGCCAT

\section{Isolation of total triglyceride-rich lipoproteins, chylomicrons, and very low-density lipoprotein}

TRLs include chylomicrons and VLDL. The two kinds of TRLs have different Svedberg flotation units due to their different triglyceride contents, with chylomicrons and VLDL $>400$ and 20-400 Svedberg flotation units, respectively ${ }^{60}$. TRLs were isolated by density gradient ultracentrifugation according to Redgrave and Carlson ${ }^{61}$ with slightly modification by Karpe et $\mathrm{al}^{62}$.
Plasma was collected from ApoC3-tg and Gpihbp1-/mice and then was stored at $4{ }^{\circ} \mathrm{C}$ for further isolation within $72 \mathrm{~h}$. Their total TRLs were isolated in normal saline (density $1.006 \mathrm{~g} / \mathrm{ml}$ solution) by density gradient centrifugation (Beckman Coulter, OptimaTML-100K) at $230,000 \times g$ for $18 \mathrm{~h}$. The white floating stratum was carefully collected and stored at $4{ }^{\circ} \mathrm{C}$ for further in vitro experiments.

Plasma was collected from three acute pancreatitis patients with hypertriglyceridemia using sodium citrate anticoagulant tubes within $48 \mathrm{~h}$ after the onset of acute pancreatitis and then stored at $4{ }^{\circ} \mathrm{C}$ for further isolation. Chylomicrons were isolated from plasma in normal saline by density gradient centrifugation (Beckman Coulter, OptimaTML-100K) at $100,000 \times g$ for $20 \mathrm{~min}$. The white stratum containing the chylomicrons was carefully collected. The remaining liquid, which was also in normal saline, was separated by density gradient centrifugation (Beckman Coulter, OptimaTML-100K) at 230,000 $\times g$ for an additional $18 \mathrm{~h}$. The white stratum containing the VLDL was carefully collected. The chylomicrons and VLDL were stored at $4 .{ }^{\circ} \mathrm{C}$ until further in vitro experiments.

\section{Assessment of plasma lipoprotein particle sizes}

Isolated TRL particles diluted by normal saline to a triglyceride concentration of $40 \mathrm{mg} / \mathrm{dL}$ were stained by uranyl acetate and then analyzed by transmission electron microscopy (JEM-1400PLUS, JEOL Ltd.) with $\times 30000$ magnification. All plasma samples diluted by normal saline to a triglyceride concentration of $40 \mathrm{mg} /$ $\mathrm{dL}$ was also measured by dynamic light scattering using a Malvern Zetasizer Nano ZS90 (Malvern Instruments, Worcestershire, UK) to determine the particle average and peak sizes, which works based on the Mie theory. Besides, the plasma was collected from mice on a normal diet. All sizes measurements were carried out at $25^{\circ} \mathrm{C}$. Then the average and peak sizes of lipoproteins were analyzed, in which the analyzed peak size of lipoproteins of wild-type mice came from the highest peak for wild-type mice presented several peaks of lipoproteins.

\section{Lipids extraction from tissues}

We extracted lipids from tissues using Folch's method $^{63}$. For the measurement of lipids in pancreatic tissue, we performed body circulatory perfusion with phosphate buffer saline $(0.01 \mathrm{M})$ before the pancreas was removed. The lipids in the pancreas were extracted by homogenizing with 2:1 chloroform-methanol $(\mathrm{v} / \mathrm{v})$, and the lipids in the organic phase were dried with nitrogen. The lipids were dissolved with 3\% Triton X-100 before measurement. 


\section{Lipid extraction from the hydrolysis solution containing triglyceride-rich lipoproteins and LC-MS detection of free fatty acids}

TRLs from ApoC3-tg and Gpihbp1-/- mice with final triglyceride concentrations at $200 \mathrm{mg} / \mathrm{dL}$ were hydrolyzed with excess pancreatic enzyme $(20000 \mathrm{U} / \mathrm{L})$ for $30 \mathrm{~min}$ at $37^{\circ} \mathrm{C}$ to release FFAs. FFA concentrations in hydrolysis solution were not significantly different between the Gpihbp1-/- and ApoC3-tg mice (data not shown). Lipids were extracted according to a modified method by Bligh and Dyer ${ }^{37,64}$ with $400 \mu$ l of chloroform: methanol (2:1) per $100 \mu \mathrm{l}$ of hydrolysis solution. The mixture was vortexed and centrifuged at $836 \times g$ for $30 \mathrm{~min}$ at $4{ }^{\circ} \mathrm{C}$. The organic solvent was evaporated with a nitrogen stream. Then, the pellets were successively dissolved in $20 \mu \mathrm{l}$ of methanol:chloroform (1:1) and $60 \mu \mathrm{l}$ of isopropanol:acetonitrile:water (2:1:1). An LC-20AD Shimadazu pump system and API 5500Q-TRAP mass spectrometer (AB SCIEX, Framingham, MA) were used for the separation and analysis. Mobile phase A was prepared with $10 \mathrm{mM}$ ammonium acetate in $60 \%$ acetonitrile with $0.5 \%$ formic acid. Mobile phase B was prepared with $10 \mathrm{mM}$ ammonium acetate in isopropanol:acetonitrile (9:1) with $0.1 \%$ formic acid. The multiple reaction monitoring (MRM) list of metabolites is shown in the Supplementary Table 2. A representative chromatograph of separation of multiple fatty acids by LC/MS from the Gpihbp1-/- and ApoC3tg mice is shown in Supplementary Fig. 8a.

\section{Primary pancreatic acinar cell isolation and cell culture}

Primary pancreatic acinar cells (PACs) were prepared based on two previous studies ${ }^{65,66}$ from adult ICR (CD1) mice. We used $1000 \mathrm{U}$ of collagenase purchased from Worthington (LS005273) for PAC isolation. The cells were cultured in DMEM/F-12 with HEPES (Gibco, Germany) at $37{ }^{\circ} \mathrm{C}$ with $5 \% \mathrm{CO}_{2}$ and used for experiments within $4 \mathrm{~h}$ after isolation. Greater than $95 \%$ cell viability was confirmed by trypan blue staining. Then the isolated cells were used for further in vitro experiments.

PACs were incubated with TRLs from ApoC3-tg and Gpihbp1-/ - mice at different triglyceride concentrations $(2.5,5,10,20$, and $40 \mathrm{mg} / \mathrm{dL})$ for $30 \mathrm{~min}$. To assess PAC necrosis and the LDH activity of the cell supernatant, Trypan Blue and fluorescent staining of PACs were performed as described above and below. Orlistat $(1 \mathrm{mM}$, Aladdin, USA) was used to inhibit the activity of pancreatic lipase and caerulein $(100 \mathrm{nM})$ to stimulate pancreatic lipase secretion in the cell culture experiments. FFAs were also measured as described as above.

PACs were incubated with chylomicrons or VLDL at the same triglyceride concentrations $(40 \mathrm{mg} / \mathrm{dL})$ from plasma of acute pancreatitis patients with hypertriglyceridemia in combination with caerulein $(100 \mathrm{nM})$. To assess PAC necrosis and the LDH activity of the cell supernatant, Trypan Blue and fluorescent staining of PACs was performed. FFAs were also measured.

\section{Pancreatic acinar cells staining}

Propidium iodide (PI, Dojindo, Japan), calceinacetoxymethyl (calcein-AM, Dojindo) and Hoechst 33342 (Dojindo) were incubated with the cells at $37^{\circ} \mathrm{C}$ and $5 \% \mathrm{CO}_{2}$ for $15 \mathrm{~min}$ at a final concentration of $1,1.5$, and $3.6 \mu \mathrm{M}$, respectively, and then were washed once for Inverted Fluorescence Microscope analysis or photographed by a high-throughput cell imaging system at the following fluorescent wavelengths: PI, $\lambda \mathrm{ex}=530 \mathrm{~nm}$ and $\lambda \mathrm{em}=580 \mathrm{~nm}$; Calcein-AM, $\lambda \mathrm{ex}=490 \mathrm{~nm}$ and $\lambda \mathrm{em}=$ $515 \mathrm{~nm}$; and Hoechst33342, $\lambda \mathrm{ex}=350 \mathrm{~nm}$ and $\lambda \mathrm{em}=$ $460 \mathrm{~nm}$. Trypan Blue (Sigma, USA) staining was performed at a final concentration of $0.01 \%$ in cell medium and then observed under optical light using an inverted microscope.

\section{Statistical analysis}

Results of animal and cell experiments were presented as mean \pm SD or mean \pm SEM. Data were analyzed with one-way ANOVA analysis of variance by Bonferroni test or by independent sample $t$-test after undergoing a normal distribution test. Histological scores were analyzed by Mann-Whitney rank-sum test. Analysis of incidence of patchy necrosis was performed with Chi-squared test. $P<$ 0.05 was considered statistically significant. All data were processed with SPSS software.

\section{Acknowledgements}

We thank Mingming Zhao (Institute of Cardiovascular Science, Health Science Center, Peking University) and Guotao Lu (Surgical Intensive Care Unit (SICU), Department of General Surgery, Jinling Hospital, Medical School of Nanjing University) for their technical assistance. We also thank Haizhao Yan and Jianglin Fan (Basic Science for Clinical Medicine/Molecular Pathology, Faculty of Medicine, University of Yamanashi) for their help on pathological analysis. This work was financially supported by the National Natural Science Foundation of China $(81660114,81860122$, and 81570787) to W.H. and Y.W.; Jiangxi Province Science Foundation for Youths (20142BAB215010) to W.H.; International Cooperation in Science and Technology Innovation Between China and Japan from Ministry of Science and Technology (MOST, 2016YFE0126000) of PR China to Y.W.; and Japan China Sasakawa Medical Fellowship to Y.W.

\section{Author details \\ 'Department of Gastroenterology, The First Affiliated Hospital of Nanchang University, 330006 Nanchang, China. ${ }^{2}$ Institute of Cardiovascular Sciences, Peking University Health Science Center, 100191 Beijing, China. ${ }^{3}$ Key Laboratory of Molecular Cardiovascular Science, Ministry of Education, 100191 Beijing, China}

\section{Author contributions}

Y.Z. performed experiments, analyzed data and wrote the manuscript. collected patients' information and evaluated data of human samples. Y.W., Y.Z., and W.H. edited the manuscript. W.H., Y.W., G.L., Y.Z., and N.L. conceived the study, supervised and directed experiments. W.H. and Y.W. provided funding. X.L., X.L., X.X., X.Z., and X.Y. assisted in carrying out the experiments. J.W., C.H., and L.L. participated in data analysis. 


\section{Conflict of interest}

The authors declare that they have no conflict of interest.

\section{Publisher's note}

Springer Nature remains neutral with regard to jurisdictional claims in published maps and institutional affiliations.

Supplementary Information accompanies this paper at (https://doi.org/ 10.1038/s41419-019-1969-3).

Received: 14 May 2019 Revised: 20 August 2019 Accepted: 26 August 2019 Published online: 30 September 2019

\section{References}

1. Zheng, Y. et al. A multicenter study on etiology of acute pancreatitis in Beijing during 5 years. Pancreas 44, 409-414 (2015).

2. Nawaz, $\mathrm{H}$. et al. Elevated serum triglycerides are independently associated with persistent organ failure in acute pancreatitis. Am. J. Gastroenterol. 110, 1497-1503 (2015).

3. Wang, S. H. et al. Relationship between plasma triglyceride level and severity of hypertriglyceridemic pancreatitis. PLOS ONE 11, e0163984 (2016).

4. Wang, Q., Wang, G., Qiu, Z., He, X. \& Liu, C. Elevated serum triglycerides in the prognostic assessment of acute pancreatitis: a systematic review and metaanalysis of observational studies. J. Clin. Gastroenterol. 51, 586-593 (2017).

5. Wan, J. et al. Stratified analysis and clinical significance of elevated serum triglyceride levels in early acute pancreatitis: a retrospective study. Lipids Health Dis. 16, 124 (2017).

6. Xiao, C., Dash, S., Morgantini, C. \& Lewis, G. F. New and emerging regulators of intestinal lipoprotein secretion. Atherosclerosis 233, 608-615 (2014).

7. Valdivielso, P., Ramirez-Bueno, A. \& Ewald, N. Current knowledge of hypertriglyceridemic pancreatitis. Eur. J. Intern. Med. 25, 689-694 (2014).

8. Rawla, P., Sunkara, T., Thandra, K. C. \& Gaduputi, V. Hypertriglyceridemiainduced pancreatitis: updated review of current treatment and preventive strategies. Clin. J. Gastroenterol. 11, 441-448 (2018).

9. Jin, M. et al. Continuous intravenous infusion of insulin and heparin vs plasma exchange in hypertriglyceridemia-induced acute pancreatitis. J. Dig. Dis. 19, 766-772 (2018).

10. Dehal, H. \& Adashek, M. Total plasma exchange in hypertriglyceridemiainduced pancreatitis: case report and literature review. Case Rep. Med. 2018, 4017573 (2018).

11. Blom, D. J. et al. Characterizing familial chylomicronemia syndrome: baseline data of the APPROACH study. J. Clin. Lipidol. 12, 1234-1243 (2018).

12. Gotoda, $T$. et al. Diagnosis and management of type I and type $\vee$ hyperlipoproteinemia. J. Atheroscler. Thromb 19, 1-12 (2012).

13. Tada, $\mathrm{H}$. et al. Clinical characteristics of Japanese patients with severe hypertriglyceridemia. J. Clin. Lipidol. 9, 519-524 (2015).

14. Berglund, L. et al. Evaluation and treatment of hypertriglyceridemia: an Endocrine Society clinical practice guideline. J. Clin. Endocrinol. Metab. 97, 2969-2989 (2012).

15. Beigneux, A. P. et al. Glycosylphosphatidylinositol-anchored high-density lipoprotein-binding protein 1 plays a critical role in the lipolytic processing of chylomicrons. Cell Metab. 5, 279-291 (2007)

16. Weinstein, M. M. et al. Abnormal patterns of lipoprotein lipase release into the plasma in GPIHBP1-deficient mice. J. Biol. Chem. 283, 34511-34518 (2008).

17. Ariza, M. J. et al. Novel mutations in the GPIHBP1 gene identified in 2 patients with recurrent acute pancreatitis. J. Clin. Lipidol. 10, 92-100 (2016).

18. Rabacchi, C. et al. Clinical and genetic features of 3 patients with familial chylomicronemia due to mutations in GPIHBP1 gene. J. Clin. Lipidol. 10 915-921 (2016).

19. Chen, W. J. et al. Hypertriglyceridemic acute pancreatitis in emergency department: Typical clinical features and genetic variants. J. Dig. Dis. 18, 359-368 (2017).

20. Norata, G. D., Tsimikas, S., Pirillo, A. \& Catapano, A. L. Apolipoprotein C-III: from pathophysiology to pharmacology. Trends Pharmacol. Sci. 36, 675-687 (2015).

21. Cohn, J. S., Patterson, B. W., Uffelman, K. D., Davignon, J. \& Steiner, G. Rate of production of plasma and very-low-density lipoprotein (VLD) apolipoprotein C-III is strongly related to the concentration and level of production of VLDL triglyceride in male subjects with different body weights and levels of insulin sensitivity. J. Clin. Endocrinol. Metab. 89, 3949-3955 (2004).

22. Cohn, J. S. et al. Increased apoC-III production is a characteristic feature of patients with hypertriglyceridemia. Atherosclerosis 177, 137-145 (2004).

23. Pavlic, M. et al. Triglyceride-rich lipoprotein-associated apolipoprotein C-III production is stimulated by plasma free fatty acids in humans. Arterioscler Thromb. Vasc. Biol. 28, 1660-1665 (2008).

24. Hegele, R. A. et al. Clinical and biochemical features of different molecular etiologies of familial chylomicronemia. J. Clin Lipidol. 12, 920-927 (2018).

25. Ito, Y., Azrolan, N., O'Connell, A., Walsh, A. \& Breslow, J. L. Hypertriglyceridemia as a result of human apo CIII gene expression in transgenic mice. Science $\mathbf{2 4 9}$, 790-793 (1990).

26. Masucci-Magoulas, L. et al. A mouse model with features of familial combined hyperlipidemia. Science 275, 391-394 (1997).

27. Havel, R. J. Pathogenesis differentiation and management of hypertriglyceridemia. Adv. Intern Med 15, 117-154 (1969).

28. Patel, K. et al. Lipolysis of visceral adipocyte triglyceride by pancreatic lipases converts mild acute pancreatitis to severe pancreatitis independent of necrosis and inflammation. Am. J. Pathol. 185, 808-819 (2015).

29. Durgampudi, $C$. et al. Acute lipotoxicity regulates severity of biliary acute pancreatitis without affecting its initiation. Am. J. Pathol. 184, 1773-1784 (2014).

30. Navina, S. et al. Lipotoxicity causes multisystem organ failure and exacerbates acute pancreatitis in obesity. Sci. Transl. Med. 3, 107-110 (2011).

31. Wang, Y. et al. Enhanced susceptibility to pancreatitis in severe hypertriglyceridaemic lipoprotein lipase-deficient mice and agonist-like function of pancreatic lipase in pancreatic cells. Gut 58, 422-430 (2009).

32. Criddle, D. N. et al. Fatty acid ethyl esters cause pancreatic calcium toxicity via inositol trisphosphate receptors and loss of ATP synthesis. Gastroenterology 130, 781-793 (2006)

33. Mateu, A., De Dios, I., Manso, M. A. \& Ramudo, L. Unsaturated but not saturated fatty acids induce transcriptional regulation of CCL2 in pancreatic acini. A potential role in acute pancreatitis. Biochim Biophys. Acta 1852, 2671-2677 (2015).

34. Chang, Y. T., Chang, M. C., Tung, C. C., Wei, S. C. \& Wong, J. M. Distinctive roles of unsaturated and saturated fatty acids in hyperlipidemic pancreatitis. World J. Gastroenterol. 21, 9534-9543 (2015).

35. Wang, Y. J., Sun, J. B., Li, F. \& Zhang, S. W. Hyperlipidemia intensifies ceruleininduced acute pancreatitis associated with activation of protein kinase $C$ in rats. World J. Gastroenterol. 12, 2908-2913 (2006).

36. Pan, $Y$. et al. Development of a novel model of hypertriglyceridemic acute pancreatitis in mice. Sci. Rep. 7, 40799 (2017).

37. Mateu, A., Ramudo, L., Manso, M. A., Closa, D. \& De Dios, I. Acinar inflammatory response to lipid derivatives generated in necrotic fat during acute pancreatitis. Biochim Biophys. Acta 1842, 1879-1886 (2014).

38. Johnston, T. P. \& Palmer, W. K. Mechanism of poloxamer 407-induced hypertriglyceridemia in the rat. Biochem. Pharmacol. 46, 1037-1042 (1993).

39. Noel, P. et al. Peripancreatic fat necrosis worsens acute pancreatitis independent of pancreatic necrosis via unsaturated fatty acids increased in human pancreatic necrosis collections. Gut 65, 100-111 (2016).

40. Jin, J. L. et al. Intensive genetic analysis for Chinese patients with very high triglyceride levels: relations of mutations to triglyceride levels and acute pancreatitis. EBioMedicine 38, 171-177 (2018).

41. Wang, T. Y., Liu, M., Portincasa, P. \& Wang, D. Q. New insights into the molecular mechanism of intestinal fatty acid absorption. Eur. J. Clin. Invest $\mathbf{4 3}$ 1203-1223 (2013).

42. Lee, J. M., Lee, H., Kang, S. \& Park, W. J. Fatty acid desaturases, polyunsaturated fatty acid regulation, and biotechnological advances. Nutrients 8, E23 (2016).

43. Maheshwari, R. \& Subramanian, R. M. Severe acute pancreatitis and necrotizing pancreatitis. Crit. Care Clin. 32, 279-290 (2016)

44. Portelli, M. \& Jones, C. D. Severe acute pancreatitis: pathogenesis, diagnosis and surgical management. Hepatobiliary Pancreat. Dis. Int 16, 155-159 (2017).

45. Zhou, J. et al. Predicting the clinical manifestations in necrotizing acute pancreatitis patients with splanchnic vein thrombosis. Pancreatology 16 973-978 (2016).

46. Jiang, W. et al. Gastrointestinal fistulas in acute pancreatitis with infected pancreatic or peripancreatic necrosis: a 4-year single-center experience. Medicine (Baltimore) 95, e3318 (2016).

47. Bakker, O. J. et al. Extrapancreatic necrosis without pancreatic parenchymal necrosis: a separate entity in necrotising pancreatitis? Gut $\mathbf{6 2}, \mathbf{1 4 7 5 - 1 4 8 0}$ (2013). 
48. Wang, M. et al. Clinical outcomes of combined necrotizing pancreatitis versus extrapancreatic necrosis alone. Pancreatology 16, 57-65 (2016).

49. Kang, R. et al. Intracellular Hmgb1 inhibits inflammatory nucleosome release and limits acute pancreatitis in mice. Gastroenterology 146, 1097-1107 (2014).

50. Huang, $\mathrm{H}$. et al. Damage-associated molecular pattern-activated neutrophil extracellular trap exacerbates sterile inflammatory liver injury. Hepatology $\mathbf{6 2}$ 600-614 (2015).

51. Szczepiorkowski, Z. M. et al. Guidelines on the use of therapeutic apheresis in clinical practice evidence-based approach from the apheresis applications committee of the American Society for Apheresis. J. Clin. Apheresis 25, 83-177 (2010).

52. Zhang, $H$. et al. Strain difference of susceptibility to caerulein-induced acute pancreatitis in mice. Chinese J. Pathophysiology 27, 2170-2174 (2011).

53. $\mathrm{Li}, \mathrm{H}$. et al. Aggravated restenosis and atherogenesis in ApoClll transgenic mice but lack of protection in ApoCIII knockouts: the effect of authentic triglyceriderich lipoproteins with and without ApoCIII. Cardiovasc. Res. 107, 579-589 (2015).

54. Sharyo, S., Kumagai, K., Yokota-Ikeda, N., Ito, K. \& Ikeda, M. Amelioration of renal ischemia-reperfusion injury by inhibition of IL-6 production in the poloxamer 407-induced mouse model of hyperlipidemia. J. Pharmacol. Sci. 110, 47-54 (2009).

55. Wasan, K. M. et al. Poloxamer 407-mediated alterations in the activities of enzymes regulating lipid metabolism in rats. J. Pharm. Pharm. Sci. 6, 189-197 (2003).

56. Johnston, T. P. The P-407-induced murine model of dose-controlled hyperlipidemia and atherosclerosis: a review of findings to date. J. Cardiovasc. Pharm. 43, 595-606 (2004).
57. Saja, M. F. et al. Triglyceride-rich lipoproteins modulate the distribution and extravasation of Ly6C/Gr1(low) monocytes. Cell Rep. 12, 1802-1815, https://doi. org/10.1016/j.celrep.2015.08.020 (2015).

58. Liu, J. et al. FTY720 attenuates acute pancreatitis in hypertriglyceridemic apolipoprotein CIII transgenic mice. Shock 44, 280-286 (2015).

59. Czako, L. et al. Hyperlipidemia induced by a cholesterol-rich diet aggravates necrotizing pancreatitis in rats. Eur. J. Pharmacol. 572, 74-81 (2007).

60. Patti, L. et al. Abnormal distribution of VLDL subfractions in type 1 (insulindependent) diabetic patients: could plasma lipase activities play a role? Diabetologia 36, 155-160 (1993).

61. Redgrave, T. G. \& Carlson, L. A. Changes in plasma very low density and low density lipoprotein content, composition, and size after a fatty meal in normoand hypertriglyceridemic man. J. Lipid Res. 20, 217-229 (1979).

62. Karpe, F., Steiner, G., Olivecrona, T., Carlson, L. A. \& Hamsten, A. Metabolism of triglyceride-rich lipoproteins during alimentary lipemia. J. Clin. Invest. 91, 748-758 (1993).

63. Folch, J., Lees, M. \& Sloane Stanley, G. H. A simple method for the isolation and purification of total lipides from animal tissues. J. Biol. Chem. 226, 497-509 (1957).

64. Bligh, E. G. \& Dyer, W. J. A rapid method of total lipid extraction and purification. Can. J. Biochem. Physiol. 37, 911-917 (1959).

65. Gout, J. et al. Isolation and culture of mouse primary pancreatic acinar cells. $J$. Vis. Exp. e50514 (2013).

66. Williams, J. A. Isolation of rodent pancreatic acinar cells and acini by collagenase digestion. Pancreapedia, https://www.pancreapedia.org/tools/ methods (2002) 